\title{
'Fixing' the Past: Modernity, Tradition and Memory in Rural Australia
}

\section{Heather Goodall}

The photograph is a quintessentially modern artefact. A captured instant of sight, frozen by non-human technology, with the illusion of objectivity. As a photograph is developed, the image comes hazily into sight, and is then caught, made static and permanent by a chemical 'fixer'. Yet 'fixing' has other meanings. To 'fix' may mean to repair and correct, or it may mean to fraudulently ensure a particular outcome, as when 'fixing' a race. Each of these three meanings is relevant to an exploration of the way rural Australians are dealing with their relationships to the past and to modernity.

A characteristic of societies moving into 'modernity' has been a shift in people's relationship to their pasts. ${ }^{1}$ The past may be seen to embody prized values and to hold the power to authorise current practices and structures. So there is strong pressure and ample opportunity to fictionalise a past, to 'invent a tradition' in Hobsbawm's memorable phrase, which will serve the purposes of a current group, whether to legimate power or to support an argument for 'restoration' of rights or values. ${ }^{2}$ When interpretations of the past are contested, a particular account may be called up to correct alleged misapprehensions or distortions in existing understandings. As Hobsbawm suggests, the 'correction' may involve a conscious or unconscious 'fixing' or deception in which the story told is shaped to privilege the interests of the group telling it. Memories, as such, are never transparent glimpses of the past but are always created in a narrative process that is shaped by questions and concerns of the narrator's present. ${ }^{3}$ So memory 
and its retelling are fertile sites for 'fixing' in the senses of 'correcting' or 'defrauding'.

But the photographic sense of 'fixing' is also important. There has been much recent discussion, after Hobsbawm, about the invention of 'tradition', but less about the ways in which 'modernity' is just as much a cultural construction which can be used to claim authority and to justify power. ${ }^{4}$ The invention of 'tradition' is invariably an argument about what 'modernity' is said to constitute and the relationship between 'modernity' and 'tradition'. Both 'modernity' and 'tradition' can be seen to be concepts created, mobilised and artificially opposed to meet shifting needs for authority.

This essay explores examples from rural Australia in which memories, in their retellings and representations, are sites for the uneasy negotiation of what is 'traditional' and what is 'modern'. It will be seen that narration of memories is not by any means a clear-cut process of laying out the constructed polarity between the traditional and the modern. Not only are these memories often mobilised to 'fix' the past in the photographic sense as well as the other meanings, but their retellings in form and content often mask the presence of the 'modern' within what is being set up as 'the past' or the 'traditional'.

The situations examined here are not simple; there are at least two layers of cultural and political interaction which complicate the picture. One is that these examples are drawn from a rural area, the Black Soil country-the northern floodplain of the Darling River, straddling north-western New South Wales and south-western Queensland. In this area, the very idea of the 'rural' is also being constituted daily, as groups locked into a number of economic and environmental conflicts align themselves to claim the authority of being the 'really' local people and so the 'real' voice of rural Australia. An even deeper complicating factor is the ongoing colonial nature of relations in the area, which shapes the way in which the 'community' is understood. The colonised Indigenous society, Aboriginal people who call themselves Murris, continue to live close to their traditional lands, which were overrun during the British invasion by the pastoral industry. Sheep and cattle graziers now find themselves facing an invasion, as intensive 
irrigated agriculture is rapidly undermining their previously secure land and political tenure. Unresolved conflicts between Aborigines and pastoralists are now compounded and complicated by the new disputes over land, water and political dominance between the two forms of western agriculture.

The realities of colonialism are starkly evident here. There is a high surviving Aboriginal colonised population. Some have faced a history of enforced or work-related movement, but many of these Aboriginal people were able to work on or near their own land. The contestation between Aborigines and non-Aborigines continues to focus on land. The tenure of graziers in the New South Wales section of the study area is pastoral lease. Although graziers have acted and thought of this tenure as if it were freehold, the rental nature of the arrangement of these leases of Crown land has been the subject of reconsideration. In 1992 the High Court recognised the continuing existence of traditional native title to property where the sovereign colonising power has not alienated the land. This affects only minimal areas in most states, but the subsequent Wik judgement in 1996 indicated that native title might also continue to exist on land under grazing lease. Now pastoralists, whether affected by any native title claims or not, are arguing that Aboriginal claims to land have interrupted their legitimate development plans. Their insecurity also arises from attempts to protect the environment with legislation. Finally, the invasion they face in both states of highly capitalised irrigated farming for cotton and intensive beef lot production has exposed the weaknesses in the grazing industry. Populations are declining, land values are destabilised and political establishments are being challenged in the confrontations over economic and civic power.

Colonialism in rural Australia and the grazing industry itself have been major sites for the exercise of modern technology and capitalist innovation in Australia. Modernity is often assumed to be an urban phenomenon, which then slowly spreads to rural areas. The rural in Europe can be imagined, however inaccurately, as an archive of residual pre-capitalist practices and knowledge. It has been drawn on in this sense as if it were a source of 'essential' national characteristics. In areas like Australia where colonisation began after the processes 
of European 'modernisation' had taken hold, the impact of modernity is as much rural as urban. In a settler colony, the pre-capitalist land use and culture is that of the colonised. And in order to justify invasion, colonised people and their culture have until very recently been denied and ignored. The ruthless violence with which the colonised peoples were supplanted is masked in Australia by an origin mythology among whites of a 'peaceful settlement'. But masked also is the degree to which pastoral expansion exemplified, not an imagined premodern rural pastoral, but the modern itself, in its repeated application of new technologies to the landscape, its rapid embrace of 'labour-saving' innovations and the continuing expectation that engineering approaches will solve resource problems, whether those of scarcity or over-abundance.

From the 1840 , new technologies like the breech-loading rifle and the telegraph and railway supported the relentless innovation required to meet the demands of the global market for wool, beef and grain products. This involved equally relentless displacement and often destruction of the existing traditions of the land, that of the Indigenous people who were being colonised. The grazing industry then survived only by being able to apply new technologies, and after World War II there was a rapid increase in the use of fossil-fuelled equipment such as trucks for droving, heavy harvesting equipment, motorbikes and later helicopters for mustering. Most recently, the introduction of intensive irrigated crops have brought the use of ever-more sophisticated computer and satellite technology, offering a promise (seldom fulfilled) of a level of control over the environment for cotton farmers of which graziers could only ever dream. This has intensified the romantic dream of achieving heightened power through technology. Even graziers, whose water and livelihood are threatened by water-hungry cotton farms upstream, will frequently become wistful as they describe the excitement of the scale and sophistication of the cotton growers' technological control over their crop and land.

Apart from the impact on the physical environment, this process has had profound human costs, as the need for labour has declined dramatically since the rise in use of fossil-fuelled machinery after 1945 . Workers have found there is no longer 
work for them in the stockyards, as drovers, or even as shearers, as new 'wide blade' shears were introduced. The network of families and relationships, which are, in themselves, what so many longer-term residents define as 'the country', has been altered and then broken up over the last two decades as more and more small-holding families have left the district.

This had led to a phenomenon often described as characteristic of post-modernity. Jameson's descriptions of this phenomenon were directed to the 'post-modern' city, in which the landmarks of a familiar social world are effaced by the homogeneity of urban modernity. The familiar signs of the social network by which people oriented themselves have been removed, causing disorientation. Ching and Creed have argued that this is just as likely to occur in rural settings, and certainly in rural Australia this is what people describe. ${ }^{5}$ In the case of non-Aboriginal country people, for whom the natural environment holds few meaningful signs, it is elements of the built environment like letterboxes along the roadside which are grieved over as they disappear.

Yet there has been a strong tendency among urban Australians to see the Australian rural experience not as 'post-modern' but as 'pre-modern', in terms of the European romantic concepts of pre-industrial cultural and economic conservatism. There has been as well a simplistic urban adoption of the tropes of 'rusticity' to denigrate non-urban communities, practices and individuals. ${ }^{6}$ At times, official presentations of the rural have fostered this view of the rural as national essentialism and given an impression of rural stasis. In many instances, rural people, or, as they recently demanded to be called, 'bush families', have fought against the denigration of rusticity, and have insisted that their past and present embrace of modernist technology and ideologies be recognised. Yet there are processes working against such recognition among rural people themselves, some deliberately mobilised but some apparently less conscious. Instead, there are contrary trends, which either obscure the modernity of the Australian rural experience or seek to supplant it with a mythology of rural 'tradition' which sets it apart from the 'modern' present and which draws on the pre-industrial pastoral of European rural myth rather than on any experience of 
either settler or colonised in Australia.

The particular self-contradiction within the agrarian myth as it has been used in settler-colonies like the United States is that it looks both backwards and forwards, denigrating modernity as it romanticises settlers' withdrawal from corrupting cities, yet at the same time celebrating modernising 'progress' as it triumphs over 'primitive' peoples and 'wasted' country.' We can see very similar ambivalences in Australian situations, although the ways in which modernity and tradition are constructed differ markedly between settler and Aboriginal uses. I will discuss two examples: one from settler and one from Aboriginal experiences. In each situation, a constructed sense of 'tradition' to seek authority for interpretations is in use, at the same time as an uneasy alignment with 'modernity'. In each, however, the tropes and tools of modernity are often the means to obscure the actual processes of modernisation in either technological or social dimensions. And in each, the past is 'fixed' in memory from a particular vantage point, which isolates the 'past' from the 'modern' present, making continuing dynamic processes into fixed, static 'traditions', and masking the deep interactions between the processes of the traditional and the modern.

\section{1. 'Battling the land': woody weeds}

A deeply disturbing occurrence for graziers in the western districts of New South Wales and Queensland is the rapid spread of native saplings which have been dubbed 'woody weeds'. These are immature forms of well-known eucalypts, such as Coolibah on black soil and Buddah bush and Turpentine on red soil. The woody weeds do not appear as single, free-standing plants like the known and often admired mature trees, but instead are growing in dense thickets, with thin, often multiple stems, blocking sunlight, obstructing vision and transforming the once open plains into impenetrable forests. The ways in which grazing managers describe their memories of the emergence of woody weeds have many common characteristics. ${ }^{8}$

Women take a major role in the work of a pastoral business, but less often in its management. ${ }^{9}$ It is men, typically, who tell the story of how the woody weeds got out of hand. There 
are few stock workers remaining in western areas since the mechanisation of the 1960 , so it is generally leaseholders and managers who narrate a history of their decision-making and explain that the regrowth started after the big floods of 1950 and 1956. There is intense debate among graziers about whether flooding stimulates or impedes native pasture regrowth, a debate which demonstrates that direct observation does not produce any consensual 'local knowledge'. Most, however, see floods as having a role in causing the dense 'weed' shrubs and saplings to emerge. Whatever the details of the initiating event, the regrowth is attributed to some external and usually unavoidable 'natural' cause. The plants are described as inherently vigorous and difficult to control, and as malevolently herbicidal: killing grass and other plant growth all around them. The sequence for the graziers is clearly that the woody weeds invade grassland and then kill the pasture. Some admit that they did not notice the saplings in their early growth phases, while others simply describe the rapid march of the plants across the plains as having been out of their control to anticipate or prevent. Many plead: 'We just want to get back to what it was before' (without any question of what 'before' might mean).

In frequently expressed, affectionate descriptions of childhoods playing and riding across open, sunny plains, shaded with scattered large gums, graziers call on a widely shared vision of the 'essential' nature of the Australian landscape, the 'open, sunlit plains' of many poems and paintings. They invoke a long-standing image of national emplacement for urban perhaps even more than for rural Australians, as close to a tradition as the settler society has yet achieved, but one which has been losing currency since the mid century as Australians' work and leisure experiences shifted to the lush coast or the dramatic and remote desert interior.

There have been increasing restrictions on clearing in New South Wales for some years now. In Queensland there have been none until recently, so that what is euphemistically called 'stick-picking' has been a yearlong occupation. Now the newly established Labor government in Queensland has foreshadowed regulations to limit clearing and as a result the last months of 1999 have seen such a wave of panic clearing 
by landholders that it has alarmed even fellow graziers in the area. In New South Wales, the National Parks Service staff (who administer regulations protecting native flora and fauna outside national parks as well as within them) and increasingly the Western Lands staff (who were once reliable advocates for the grazing industry) are both now seen as under the influence of 'The Greens'. The villains in many of the graziers' stories are consistently the anonymous 'Greens' of the cities, who are seen as ignorant of rural conditions but as vindictively dominating political processes and controlling the rural officials. The heroes are the graziers themselves, seeking now to restore the sunlit, open plains.

Another narrative could be constructed, however, and the differences in the two accounts suggest the omissions in and shaping of the graziers' story. The major environmental impact of grazing was in the 1870 s and 1880 s and led to dramatic soil change and the virtual extinction of many species of plants and animals. Aboriginal fire management of the grasslands was stopped around the same time, and the rabbit plague added to the destructive collapse of grazing lands in the 1890 . Since the resulting reduction in grazing pressure, the effects have been much slower and less obvious. The dramatic changes are now beyond living memory, but the impact has nevertheless continued to undermine the diversity of native pastures, depleting ground cover. Most scientific observers agree that the regrowth occurred after the pasture was destroyed: the saplings increase to 'fill a vacuum' on effectively denuded land. ${ }^{10}$ This is diametrically opposed to the causal relation established in the grazier narrative, and demands that grazing itself accept the major responsibility for the sapling advance.

One of the reasons the sequence of events is disputed is because of the advent of technological modernity onto the grazing lands. With accelerated mechanisation after World War II, as the wool boom profits were turned into motorbikes, planes and helicopters, the number of boundary riders and stock workers rapidly declined. There was also, perhaps as a generational change, an ethnic shift in rural populations, with fewer of the Chinese men who had formed so many of the scrub-cutting and ring-barking gangs of the pre-war years. 
With less employment, there was no further need for resident Aboriginal labourers. The Aboriginal workers' camps on the large properties were finally broken up and their residents forced away to the region's small towns. The overall effect was that there were fewer people, fewer eyes, to see the early stages of the regrowth until the saplings had taken a strong hold and grown too large to be readily removed by hand or boot. The rapid break up of larger properties into small-scale selections after the war exacerbated the problem, disrupting the flow of experienced information and individualising the observation process, leaving small-scale family farmers with few workers and no senior staff for advice and to share decision-making. There were at the same time fewer rabbits, thanks to the modern scientific strategy of the deliberate introduction of myxomatosis, and so pressure on the young plants was rapidly reduced just when there were fewer people there to watch them spring away.

The style of first person narration, the autobiographical form of individual testimony, is a literary and oratorical genre which is associated with the individualism of modernist literature and the individualism said to be characteristic of modernity itself. This is the form of narrative which grazing landholders and managers always use to describe their knowledge of their land. It conveys an impression of unchanging personal supervision of land conditions, consistent with both the intensely individualistic rhetoric of all contemporary rural business people in Australia and the masculine ideal of a responsible individual head of family. Yet early pastoral concerns were run with massive workforces, and the managers and graziers depended on the information they were given regularly by workers on all levels. That close, personal observation all disappeared with mechanisation, or was disrupted and truncated with selection. But this major shift is masked in grazier narratives which suggest continuous sole, personal knowledge of the land and of decision-making.

The 1970 s saw the rapid development of environmental consciousness in urban areas, and a slow shift in the attitudes of personnel in land supervision roles. As public pressure increased for measures to protect the environment, the members of land management bureaucracies began to see themselves 
responsible to a wider constituency (often expressed as 'the public' or 'the future') rather than to rural primary producers. At the same time as economic rationalism held sway in both conservative and centre-left governments, leading to a deregulation of tariffs and industry protection, agriculture has faced a rising number of regulations relating to land management. The combination of shifting regulations and growing reluctance of officials to condone local transgressions of the new restrictions led to a dramatic slowdown in New South Wales in approvals to clear land of any vegetation. Grazier frustration was intensified as economic conditions declined, cyclic drought set in and growing anxiety about increasing intensive irrigation and clearing for cotton slowed approvals of clearing licences down to a dead stop. In this situation the Wik debate appears like a god-send: now these constraints can be blamed on Aboriginal Native Title claimants and the rural representatives in parliament can be lobbied to remove all obstructions in one go.

In seeking a solution to this impasse, some graziers are re-narrating their history. For the first time, they are acknowledging not only Aboriginal presence before the invasion, but recognising the value of fire management of grasslands. ${ }^{11}$ They are appealing to a new view of Aboriginal traditional land management as active, and they are portraying themselves as the inheritors of these techniques and of a custodial, conservationist approach to land. Some are doing this opportunistically, with no consultation with or role at all for local Aboriginal owners, while others are more sensitive to the need, even in cosmetic terms, for collaboration with continuing Aboriginal populations.

This realignment is a major shift in political relations in the region, born out of two crises, the shared opposition to cotton irrigation and the perceived biological threat of woody weed. For most pastoralists, however, their accounts of the rise of the woody weed crisis give them a framework within which to define their enemies, but few clues about how to address the problem in an achievable way. Their memories of the past environment as having an 'essential' and timeless norm of open paddocks and sunlit plains allow no insight into the way the very modernity of their own methods 
and economic choices have contributed to environmental changes.

\section{Traditional owners and native title}

Aboriginal people in the Black Soil country have had different but no less complex engagements with both tradition and modernity. The invasion by the British in this pastoral area from the 1830 s was extremely brutal until the early 1850 , causing major depopulation. Then the gold rushes drew European labour away from the pastoral industry so dramatically that Aboriginal people found themselves encouraged back onto their own lands by the very squatters who had been chasing them so violently away only the year before. This shift in conditions allowed Aborigines to establish themselves in most grazing areas as a permanent minority of the pastoral labour force until the mechanisation of the 1950 and 1960s. ${ }^{12}$

The slow rebuilding of social relations between surviving Aborigines during the mid nineteenth century was undertaken in the conditions imposed by the modernising pastoral industry. Yet the retention of links to traditional country allowed people to draw on the remaining formal oral traditions about their land. Perhaps even more importantly, however, what continued was the practice of 'tradition' as process. By this I mean that the 'traditional' influences on Aboriginal people in this radically different and modernising context were not simply the conserving of discrete stories and items of information about laws and the meaning of sites, but the continuation of the expectation that land would be meaningful and that this would, in turn, foster reciprocal and sustaining relations between people. This understanding of tradition as process is quite different from the frequent definition of 'tradition' as a fixed body of knowledge or a set of unchanging closed narratives, separated from the present. I have argued that this continuing practice of traditional expectations has been strongly evident in New South Wales throughout the period under colonialism. ${ }^{13}$

It has been conclusively and repeatedly demonstrated that Aboriginal cultural tradition is subject to change and creative reinterpretation, precisely because it has the vitality of any living culture in being able to engage with changing 
conditions. ${ }^{14}$ Hobsbawm calls this 'custom', distinguishing it from the 'invented' 'tradition' which is necessarily inflexible to act as an anchor against change. 'Custom', he writes:

does not preclude innovation or change up to a point, though the requirement that it must appear compatible or even identical with precedent imposes substantial limitations on it. ${ }^{15}$

Nevertheless, it is also clear that Aboriginal cultures have sustained an ideological conviction that knowledge about land and the relations between people and land were eternal truths, handed down from the distant (as well as coexistent) dreaming/creation time, and were not and never had been open to change by human creativity or agency. This 'naturalisation' of the permanence of cultural constructs, despite the fact that they can be conclusively shown to be subject to change, is one source of confusion about the degree to which 'tradition' may be malleable. There have, however, been pressures arising from the conditions of a modernising colonialism which may have resulted in an even stronger emphasis by Aboriginal people on the permanence of Aboriginal tradition.

One may have been the invasion itself, which occurred with what must have seemed at times to be such implacable force. Stories of traditional powers and beings continue to be widespread throughout the many Aboriginal communities in New South Wales, and they were recorded in their colloquial, everyday retelling by observers like writer Roland Robinson during the 1930 . ${ }^{16}$ While these stories have obviously been a sustaining element in Aboriginal identity over two centuries, my impression has been that the New South Wales stories, when compared to those in areas like the Western Desert where the impact of invasion was later and less devastating, are notably focused on compelling narratives of overwhelming, retributive power. The underlying boast of the British that they embodied change and innovation may have prompted Aboriginal people to emphasise their culture as unchanging in a defiant assertion of difference and a claim for great authority. Since the early twentieth century, however, there has been a rising desire among settler Australians to seek an 'other' 
which offers apparent permanence and assured truths, as well as immemorially established relations with invaded land. This has led European Australians to a revaluation of indigenous 'tradition', which includes a pressure to assume the most rigid and static nature of that 'tradition'. ${ }^{17}$

Yet, through the whole period of colonisation, Aborigines have unavoidably worked within and had to negotiate modernising economic and social and cultural processes. This has seldom involved an unconditional acceptance of British practices or values, and one of the most hated impositions has long been the way in which state administrative bodies like the Protection Board and the Education Department used distinctions based on skin colour and assumed biological descent to categorise and govern Aborigines. These hated 'caste' hierarchies were used for decades to decide which children would have access to 'public' schooling; which people could live with their families on land defined by the state as 'reserve' or which were to be hunted off with expulsion orders; and which people were most eligible for 'dog tags' or certificates exempting them from the restrictions of the Aborigines Protection Act. This desire by settler bureaucracies to classify and order Aboriginal people by biological characteristics was a widely used practice deriving from the instrumental rationality which Weber and others have identified as characteristic of western modernity. ${ }^{18}$ Time and again, Aborigines asserted the broader and more encompassing nature of traditional kinship and many battles were fought out to reaffirm this in practice, with people sharing houses in defiance of Board restrictions; families visiting kin, sharing money and other resources, rather than build up the bank accounts on which the Board insisted; leaving work to attend funerals. In many ways, Aborigines in New South Wales have challenged the colonial bureaucracy's attempt to impose a narrow, biologically based system of placing and ordering people.

The strong continuities in Aboriginal practice around kin is suggested in the ways family stories are told, and in the ways these differ from the approaches of other local histories. There have now been a number of Aboriginal family stories published in written form from the northwest, all chronicling the links between (extended) families and places and the 
movement between them. ${ }^{19}$ These stories often show supralocal identification, with connections traced to other speakers of the same language or those with shared political affiliations across a region and Australia wide. At the same time, they each demonstrate an intense localism, with the particulars of land and place inevitable elements of the most simply told tale. This way of telling stories can be compared with the way Aboriginal and other families are presented in the local history volumes, where land and place figure only as obstacles or possessions, where people are defined by their jobs and their adherence to particular behaviours, and where connections more lateral than the nuclear family are seldom emphasised.

Now a new situation has arisen which has complicated still further the negotiation between tradition and modernity, between past and present, for Aboriginal people. Largely as a result of continuous Aboriginal campaigning over many decades, the prior rights of Aboriginal people to property in land as well as to many forms of cultural expression have been formally recognised by mainstream Australian legal and political systems. This has been expressed in the term 'traditional owners', which, like its variant, 'native title holders', has not yet been even loosely defined by anyone. It is, however, being applied to an increasing number of bureaucratic processes, from the management of national parks to negotiations over intellectual property to the settling of claims to land under native title. While many Aboriginal people feel confident of the appropriateness of these terms in the general sense, they are increasingly being forced to offer detailed and authoritative 'proofs' of 'traditional ownership' in terms that satisfy these varied bureaucratic and legal contexts. Where Northern Territory Aboriginal people were forced to justify their claims to land in the courts, they insisted on appearing in person to sing the songs of their country. This forced the courts to accept, as at least partial proof, their performance of the knowledge which only owners can come to possess, having fulfilled obligations towards the country by participating in the requisite ceremonial tasks.

As Merlan and others have pointed out, this has precluded much of the contemporary Aboriginal understanding of the significance of place which have derived from the continued 
workings of tradition as process under colonised conditions of pastoral and town life. ${ }^{20}$ These continually reinterpreted perceptions of significance are the result of the same cultural processes as those of more 'traditional' appearance, but their association with the material life and chronology of the European occupation makes them less acceptable to the court as 'proof' of tradition. As colonisation in the Northern Territory has been relatively recent and there has been so heavy a dependence on tradition-oriented Aboriginal labour, much cultural knowledge remains about pre-invasion practices and so at least some Aboriginal owners have been able to satisfy the courts as to their 'traditional' credentials.

In New South Wales, however, colonisation began with so much brutality and has been underway for so long, that the processes of traditional life have been significantly reshaped in the conditions of modern living in rural, pastoral life. There are authoritative cultural expressions which allow performance of the evolving 'traditional', but they are not easily recognised by Europeans (demanding and yearning for a fixed and 'primitive' Indigenous tradition) as separate from a present-day, 'modern' lifestyle. Such practices include, for example, the tending of cemeteries and burial sites as a means of passing on collective, extended family histories and the many but often subtle differences in content and structure in the telling of family and community stories. Rather than being acknowledged as the outcome of vital, growing cultures, such contemporary Aboriginal knowledge has been labelled as 'not enough' to allow proof of the maintenance of tradition.

The outcome of the Yorta Yorta Native Title case is a good example of the rejection of contemporary and post-invasion knowledge as authoritative. In that case, an extraordinarily well-identified and articulate community, which had made over twenty attempts since the 1870 s to have their rights to ownership of and access to what they had always understood to be their lands, found their claims to the Barmah State Forest on the Murray River dismissed because it was said that:

the tide of history has indeed washed away any real acknowledgement of their traditional laws and any real observance of their traditional customs. ${ }^{21}$ 
The increasing demands made by the structures set up to recognise Aboriginal rights have been for 'proof' which can be 'fixed' in the past and given the authority of a closed 'tradition' deriving from a pre-invasion time. Then the claimants must demonstrate that they have a link and increasingly the grounds for proving such a link have been narrowed to being only a link by linear, biological descent to the individuals confirmed to have participated in this distant, traditionalised past. Consequently, more and more Aboriginal communities are turning to the available European documentation to search for traces of continued traditional practices and for evidence of family lines which can be traced from the nineteenth century to the present claimants.

For some decades now, Aboriginal community historians have been using just such historical resources for community histories. But such sources have been used as supplements to the remembered accounts of life stories. Archival documentation has seldom been privileged over memory where recording and compiling Aboriginal community history has been the intention. Now, however, the structures for recognising Aboriginal traditional rights have reversed this process. Life stories and contemporary understandings are now seen as lacking necessary links to the distant 'traditional' past which falls far outside the reach of living memory. So contemporary knowledge must be secondary to 'real proof' of the nature of that acceptable, authoritative 'tradition' authenticated by evidence from archival documents.

The documents being used have many strengths, but also have considerable limitations. All are the products of their colonial context and each carries its perspectives and limitations. The records of pastoral labour forces, for example, can give strong testimony to the general association over generations of families of Aboriginal people with tracts of land. But these records associate Aboriginal names with the boundaries of leases and selections. Aboriginal people were able to sustain continuing contact with their own country by living and working on pastoral properties, but their actual usage of some particular areas of the land rather than others, their movements over lease boundaries and the incongruity between traditional meanings for land and those surveyed 
lines demarking leaseholders' boundaries, do not find any record in the old wages books. The reality of recruitment to the pastoral labour force arose from more than Aboriginal choice. Networks of relationship between pastoral employers made it more likely that the people known to a pastoral manager's friends or relations would get jobs. And Aboriginal men from a clan group which gained early familiarity with stock work could gain an advantage, becoming the more readily employed workers across a wider district while less experienced traditional owners were overlooked. Such complexities of the historical process of adjusting to the colonising industry mean that the industry's archives cannot be read off as a transparent record of the underlying pre-colonial relationships, however they may have been shaped by the earlier culture. Instead, if these colonial records are preferred they will distort the understanding of 'traditional' lands into conformity with the run-holders' fence lines. ${ }^{22}$

Another similarly limited source now frequently being used are the genealogies drawn up by anthropologists like Norman Tindale in the late 1930s. ${ }^{23}$ Tindale's survey is important because of its wide geographic cover and its recording of the location of many people, along with photographs of them, at a particular time. It was, literally, a snapshot of the Aboriginal population in 1938. The Tindale 'family trees', however, were constructed entirely in terms of biological descent, in a time when much anthropological interest continued to be on 'caste' - that is, on biological descent, however speculative that may have been. While there are occasional interesting details about language affiliation of the people recorded and photographed, the sparse accompanying documentation gives few clues to the ways in which the Aboriginal people concerned may have thought of 'traditional' kin relationships, for this field survey aimed for breadth of geographical cover rather than depth of cultural observation. Nor was there any attempt to trace the realities of 'adoptive' or 'rearing up' relationships in which kin other than biological parents raised children. The complexities of actual family and land relationships under the conditions of a traditional practice shaped within colonial pastoralism and agriculture are not even acknowledged in these genealogies, let alone recorded. 
What is recorded is reported biological descent. A third major source, the Aborigines Protection Board records, is even more limited, equipped only to trace biological descent rather than any broader kin affiliation and land relation processes.

So the outcome of the bureaucratic and legal demands for 'proof' of traditional ownership have increasingly been to privilege the evidence of European-authored archives to glean evidence of 'tradition' as past product, over the process of present enactment of traditional influence. Just as important, these demands have privileged biological descent over anything else. It is a great irony that the use of one of the most hated aspects of state control has been fostered by the structure set up, after decades of Aboriginal political struggle, to ensure the recognition of Aboriginal culture and rights.

A number of Aboriginal communities have tried to protect themselves by asserting the authority of memory and of community-generated modes of identifying 'traditional owners', such as developing histories of movement patterns from community memories as well as documents (Mutawintji) and deepening research into the family histories of people known to have been buried in Aboriginal cemeteries, thus identifying the families who have called these places 'home' (Collarenebri). But for many communities the demands for proof resting on archival documentation have undermined confidence in community members, who are no longer said to be authoritative 'enough' to secure a claim. The research process even within Aboriginal communities has shifted from recording memories first and seeking archival evidence later to one of putting primary energy into archival research and only later seeking corroboration in the memories of community members. The triumph of 'tradition', conceived as a fixed product in the past and authenticated primarily from within the documentation of the colonisers, has been turned against the faithful interpreters of tradition in a culture living with modernity.

\section{Conclusion}

Both Aboriginal and non-Aboriginal people are engaged in contestations over what is 'traditional' and what is 'modern' in their experience. In a context where each of the concepts 
of 'modernity' and 'tradition' has such powerful political force, there are some benefits for the groups in defining and mobilising a definition of a fixed 'tradition', but there are problems too. None of the rhetorical positions which oppose a 'fixed' 'tradition' to a changing 'modern' offers an adequate representation of a complex present. In each situation, the mode of storytelling is implicated in the goal of 'fixing' the past into a static tradition, and in constructing the oppositions which are being created to give authority and legitimacy to those composing the story. As the threads of each story are drawn apart, and the complexities, contradictions and ironies become apparent, a remaining commonality is that each reveals the deep interpenetration of 'tradition' and 'modernity' in rural Australia.

\section{Reflection}

This essay was written in 1999, four years after the beginning of what looked at first like a routine cyclical drought where these two examples are set, in western New South Wales. Although the underlying theme of both examples was environmental fragility, the enormity of the drought had not hit home. The invasive emergence of 'woody weed' reflected the damage done by European pastoralism over a century, despite the attempt to blame it on 'nature'. Less obviously, but still environmentally based, the rising demand for documents and biology to authorise native title claims had emerged from the long competition over scarce resources in meaningful places, which had typified the invasion of Australia.

Were this essay then to be written today, there would be no avoiding the urgency of environmental crisis. The drought, which looked routine in 1999, had become a disaster after the east of Australia endured eleven years in its grip. Crops and stock were dying, farming enterprises were falling into bankruptcy and farmers themselves were suiciding. Then, from 2010, extraordinary rains provoked more crises. Flood after flood followed until 2012, when flooding spread along the eastern half of the continent. And now, in 2014, drought is threatening again in western New South Wales and Queensland.

From the early days of settler observation, it was clear that the Australian environment was not predictable in any sense. The problem for settlers was the variability of Australia's climate, 
which meant that Dorothea Mackellar's 'land of droughts and flooding rains' has seemed to be a stable - if inconvenient - truth. Now, with the threat of climate change, the increasing probability is not of cycles of even partially predictable droughts and rains, but of rising levels of catastrophic disasters as the scale of the weather extremes escalates.

This article draws from conflicts over the fragility of what can seem like a tough continent, where settler narratives have emphasised the 'battle' with an implacable nature. Now it is the continent itself, with the planet, which seems vulnerable. Despite a widespread resistance to recognising climate change, the damage in grasslands has shaken everyone's confidence. Discussions about 'El Nino' are heard more frequently around the pubs and stores in the bush today, and uneasy questions about how to hold climate change at bay-or compensate for its effects-lurk beneath most conversations. Both the settler and Aboriginal strategies for 'fixing' the past seem even more futile than they did fifteen years ago.

\section{Notes}

Alan O'Shea, 'The English Subjects of Modernity' in Mica Nava and Alan O'Shea (eds), Modern Times, Routledge, London, 1996, pp. 7-37.

2 Eric Hobsbawm, 'Introduction: Inventing Traditions' in Eric Hobsbawm and Terence Ranger (eds), The Invention of Tradition, Cambridge University Press, Cambridge, 1983, pp. 1-14. Hobsbawm and Ranger's distinctions between 'tradition' and 'custom' are valuable (if sometimes internally contradictory) but are not consistent with the current uses of the word 'traditional' in the Australian context. So here I continue to use 'tradition' to refer to both ever-changing 'custom' and to the inflexible forms of 'invented' tradition.

3 Paula Hamilton, 'The Knife Edge: Debates about Memory and History' in Kate Darian-Smith and Paula Hamilton (eds), Memory and History in Twentieth Century Australia, Oxford University Press, Melbourne, 1994, pp. 9-32; Heather Goodall, 'Aboriginal History and the Politics of Information Control' in Richard White and Penny Russell (eds), Memories and Dreams: Reflections on Twentieth Century Australia, Allen and Unwin, Sydney, 1996, pp. 77-96.

4 For a discussion of the need to explore the construction of 'modernity' rather than 'tradition', see Ralph A. Litzinger, 'Memory Work: Reconstituting the Ethnic in Post-Mao China', Cultural Anthropology, vol. 13, no. 2, 1998, pp. 224-55. Frederic Jameson, Post-Modernism, or the Cultural Logic of Late Capitalism, Duke University Press, Durham, 1991; Gerald W. Creed and Barbara Ching, 'Recognising Rusticity' in Gerald W. Creed and Barbara Ching (eds), Knowing Your Place: Rural Identity and Cultural Hierarchy, Routledge, New York and London, 1997.

6 Raymond Williams, The City and the Country, Chatto and Windus, London, 1973; Creed and Ching, 'Recognising Rusticity'.

7 Donald Worster, 'Beyond the Agrarian Myth' in his Under Western Skies: Nature 
and History in the American West, Oxford University Press, Oxford, 1992, pp. 3-18. Heather Goodall, 'Telling Country: Memory, Modernity and Narratives in Rural Australia', History Workshop Journal, vol. 47, 1999. Margaret Alston, Women on the Land: The Hidden Heart of Rural Australia, UNSW Press, Sydney, 1995.

N. C. W. Beadle, The Vegetation and Pastures of Western New South Wales, with special reference to soil erosion, NSW Department of Conservation, Government Printer, Sydney, 1948; A. D.Wilson, 'The Effects of Grazing on Australia's Ecosystems', Proceedings of the Ecological Society of Australia, vol. 16, 1990, pp. 235-44; A. D. Robson, 'The Effects of Grazing Exclusion and Blade Ploughing on Semi-arid Woodland Vegetation in North-western New South Wales over 30 Months', Rangelands Journal, vol. 17, no. 2, 1995, pp. 111-27. D. Lucas, 'Growing a "Useful” History: Narrative, Ecology and Resource Management', Public History Review, vol. 5/6, 1996/7, pp. 200-10.

12 Jeremy Beckett, 'George Dutton's Country: Portrait of an Aboriginal Drover', Aboriginal History, vol. 2, 1978, pp. 2-31; Heather Goodall, Invasion to Embassy: Land in Aboriginal Politics in NSW, 1770 to 1972, Allen \& Unwin, Sydney and BlackBooks, Sydney, 1996; Barry Morris, Domesticating Resistance: The Dhan-gati Aborigines and the Australian State, Berg, Oxford, 1989.

13 Heather Goodall, Invasion to Embassy, pp. 1-19; 98-103. Francesca Merlan has analysed the relation to 'tradition' of Aboriginal people in Katherine in the Northern Territory in a similar way in her Caging the Rainbow, University of Hawai'i Press, Honolulu, pp. 235.

14 E. Kolig, 'Noah's Ark Revisited', Oceania, vol. 53, 1983, pp. 118-32; Fred Myers, Pintupi Country, Pintupi Self, Smithsonian, Washington and AIAS, Canberra, 1986; Deborah Bird Rose, Hidden Histories: Black Stories from Victoria River Downs, Humbert River and Wave Hill Stations, Aboriginal Studies Press, Canberra, 1991; Merlan.

15 Hobsbawm, p. 2.

16 In, for example, Roland Robinson, The Man Who Sold His Dreaming, Currawong Publishing Co. Sydney, 1965 and Roland Robinson, Black Fella, White Fella, Angus and Robertson, Sydney, 1958.

17 Merlan, pp. 232, 235.

18 See discussion in O'Shea, pp. 8-17.

19 Janet Mathews (ed.), The Two Worlds of Jimmie Barker, AIAS, Canberra, 1977; Evelyn Crawford, Over My Tracks, Penguin, Melbourne, 1993; Joe Hirst, Welcome to Brewarrina (Photographic Exhibition, 1989). See parallels with life stories from other areas in New South Wales and Queensland: Margaret Sommerville, Marie Dundas, May Mead, Janet Robinson and Maureen Sulter, The Sun Dancin', Aboriginal Studies Press, Canberra, 1994; Jeanie Bell, Talking about Celia:

Community and Family Memories of Celia Smith, University of Queensland Press, Brisbane, 1997 and Phillip Pepper (with Tess de Araugo), You Are What You Make Yourself To Be, Hyland House, Melbourne, 1980.

20 Merlan, pp. 209-28.

21 Justice Olney, Federal Court of Australia, 1998, cited in AIATSIS Native Title Unit, Native Title Newsletter, vol. 3, no. 4, 1999.

22 This issue can be seen emerging in the disputes over the Indigenous Land Corporation's purchase of Eurool property, near Collarenebri, during the mid 1990s.

23 Held in the Museum of South Australia and now widely used by many Aboriginal claimant groups to try to identify biological links 